Review Article

\title{
THERAPEUTIC POTENTIAL OF PLANT-DERIVED OLIGOSTILBENES AND STILBENE GLYCOSIDES
}

\author{
SUTAPA BISWAS MAJEE ${ }^{*}$, DIPANJANA ASH², DHRUTI AVLANI ${ }^{3}$, GOPA ROY BISWAS ${ }^{4}$ \\ ${ }^{1 *}$ Department of Pharmacy, NSHM Knowledge Campus, Kolkata-Group of Institutions, 124, B L Saha Road, Kolkata 700053, West Bengal, \\ 2Department of Pharmaceutics, BCDA College of Pharmacy and Technology, 78/1 Jessore Road (S), Hridaypur, Barasat, Kolkata 700127 \\ West Bengal, ${ }^{3}$ KLE College of Pharmacy, Bengaluru 560010, ${ }^{4}$ Department of Pharmaceutics, Guru Nanak Institute of Pharmaceutical \\ Science and Technology, 147f, Nilgunj Road, Sahid Colony, Panihati, Kolkata 700110, West Bengal \\ Email: sutapabiswas2001@yahoo.co.in
}

Received: 10 Jul 2020, Revised and Accepted: 08 Sep 2020

\begin{abstract}
Stilbenoids constitute a major class of plant-derived secondary metabolites occurring in abundance across several families and are well-known for their nutritional and health-promoting benefits. Several investigations have established their therapeutic potential in the management of different types of cancer, neuroinflammation, arthritis, disorders in lipid metabolism, microbial infection etc. Studies on resveratrol monomer, oxyresveratrol, their synthetic analogs, piceatannol, pterostilbene can be found in the literature. But a collective and comprehensive review on chemistry, pharmacological effects, structure-activity relationship and pharmacokinetics of plant-derived oligostilbenes and stilbene glycosides is missing. These phytochemicals are generally characterised by poor oral bioavailability due to extensive first-pass metabolism and conjugation. The present chapter aims to fill up these lacunae and also focuses on further studies that can be performed in the future to translate these immensely potential secondary metabolites into human clinical setting from cell culture and animal studies at the preclinical level for effective therapeutic intervention of various pathological conditions.
\end{abstract}

Keywords: Bioavailability, Chemopreventive, Cytotoxicity, Neuroinflammatory, Pharmacokinetics, Oligostilbene, Resveratrol, Secondary metabolite, Stilbene glycoside and SAR

(C) 2020 The Authors. Published by Innovare Academic Sciences Pvt Ltd. This is an open access article under the CC BY license (http://creativecommons.org/licenses/by/4.0/) DOI: http://dx.doi.org/10.22159/ijcpr.2020v12i6.40297. Journal homepage: https://innovareacademics.in/journals/index.php/ijcpr

\section{INTRODUCTION}

Stilbenoids are non-flavonoid polyphenolic multi-faceted bioactive secondary metabolites found in abundance in fruits, leaves, bark and wood of numerous plants belonging to Vitaceae, Dipterocarpaceae, Leguminosae, Fabaceae, Gnetaceae, Moraceae, Polygonaceae and Cyperaceae families. Dietary items such as grapes and other related substances constitute major sources of this group of secondary metabolites, primarily resveratrol $[1,2]$. High concentration of stilbenes has been reported in passion fruit (Passifloraedulis) [3]. Stilbenoids, a prominent group of secondary metabolites, are considered as phytoalexins as they are synthesised naturally from phenylpropanoids in response to pathogenic attack and diseases, biotic and abiotic stress factors, environmental stress and UV lightinduced damage, confer selective advantage and contribute significantly to bacterial root nodulation and coloration and provide protection against toxins $[4,5]$. The most commonly occurring monomeric stilbenes are E-resveratrol and E-piceid in berry skin and these isomers may undergo different types of biotransformation reactions to produce glycosylated, methoxylated derivatives and also to yield isomers and oligomers. Stilbene glycosides synthesized de novo in plants participate in storage, confer protection against peroxidation and are transported form cytoplasm to apoplasm [3]. Apart from their antimicrobial defense actions, hydroxystilbene glucosides, isorhapontin (isorhapontigenin-0-glucoside), astringin (piceatannol-0-glucoside) and piceid (resveratrol-0-glucoside) are considered as lignin monomers and are incorporated by coupling and cross-coupling reactions during lignification in Norway spruce bark to form stilbenolignans, gnetumonin $\mathrm{B}$, gnetumonin $\mathrm{C}$, gnetofuran A and gnetucleistol [6]. Stilbenes have demonstrated a diverse range of biological functions, health-promoting effects through complex specific and non-specific mechanisms. Stilbenes may be developed as chemopreventive and chemotherapeutic agents against different forms of cancers in animals and humans, as evident from various in vitro and in vivo studies on different cancer cell lines such as colon, breast, prostate, pancreas, melanoma, lung and others [7-9]. Although the trans-isomer of stilbene is usually the most stable one and found to possess anticancer activity, combrestatin A-4 $\left(3,4,5,4^{\prime}\right.$-tetramethoxy- $3^{\prime}$-hydroxy-cis-stilbene), isolated from Combretumcaffrum is a cis-stilbene which is reported to show cytotoxic activity against several cancer cell lines [10].

Numerous studies in the past have focussed on production, biosynthesis, isolation, characterization, and various pharmacological effects of dietary stilbenes or stilbenes from medicinal plants of Africa or Croatia or Australia [11-15]. Several investigations have revealed interesting observations on the therapeutic potential of resveratrol, oxyresveratrol, piceatannol, pterostilbene and naturally occurring resveratrol analogs as well as structurally modified oxyresveratrol [16-29]. Synthetic derivatives of resveratrol and other stilbene analogs are also reported [30-32]. Although oligostilbenesalso have been subject of attention, but no comprehensive review could be found on different aspects of oligostilbenes of plant origin, focusing on pharmacological effects, structure-activity relationship (SAR), pharmacokinetics etc. Stilbene glycosides as a group have been particularly left out as evident from literature survey. Drug discovery and development based on natural products exploiting privileged scaffolds present in Mother Nature's laboratory is the key to success in pharmaceutical industry. Therefore, elucidation of the mechanism of action of oligostilbenes and stilbene glycosides will undoubtedly create unforeseen scope for scientists in the future. Keeping this in mind, the present review aims to provide an insight into the therapeutic potential of plantderived oligostilbenes and stilbene glycosides.

\section{Chemistry and biosynthesis of stilbenes: Brief background}

The basic skeleton of stilbene is characterized by a 1,2diphenylethylene nucleus, composed of two benzene rings ( $\mathrm{A}$ and $\mathrm{B}$ ), joined by an ethylene bridge, due to which cis-and trans-isomers may be obtained. Most commonly occurring phytostilbenes are based on trans-resveratrol structure and may exist in free form (aglycone) as a mixture of monomers, dimers, octamers and other complex oligomers formed by condensation of monomers and also as metabolites (glucosides) $[5,14,33,34]$. Stilbenes with 
substituents of different types and at different positions in any of the rings, of different steric configurations in free form or in their glucosidic form were isolated from leaves, heartwood and bark of pine and Eucalyptus species [35]. Prenylated stilbenes, trans-4isopentenyl-3,5,2',4'-terahydroxystilbene, trans-4-(3-methyl-E-but1-enyl)-3,5,2',4'-tetrahydroxystilbene were obtained from the stem bark of Artocarpuscommunis, M. schweinfurthii and M. alnifolia [13, 36].

Stilbenes, plant polyketidesare biosynthesised through shikimatederived phenylpropanoid and acetate-malonatepathways [37]. pcoumaroyl-CoA acts as precursor for biosynthesis of stilbenes in plants. Stilbene synthase converts cinnamoyl CoA, utilises 3 units of malonyl CoA and is involved in aldol-type cyclisation (carbon 2 to carbon 7) and decarboxylation to produce resveratrol [4, 5]. Occurrence of pinosylvin synthase and dihydro-pinosylvin synthase is reported in the literature [38]. Biosynthesis of plant stilbenes in recombinant $E$. coli has been reported to yield functionalized stilbenes [39].

\section{Oligostilbenes}

Peroxidase isoenzymes located in the cell wall, apoplast and vacuole catalyse oxidative coupling of E-resveratrol or other stilbene monomers to form oligomer stilbenoidsor oligostilbenes which are basically hydroxylated stilbenes $[3,40]$. They can be categorised into two groups, consisting of compounds with 5-membered oxygen heterocyclic ring, with trans-2-aryl-2,3-dihydrobenzofuran moiety and a second group lacking oxygen-containing heterocyclic ring, such as pallidol [41]. Polyphenol-type resveratrol dimer, trimer and tetramers were isolated from the stem portion of Vitisthunbergii var. taiwaniana [42]. A resveratrol dimer, ampelopsin A was detected in grapevine shoot extracts and in Ampelopsis glandulosa [37]. Other oligostilbenes extracted from grapevine root extract include $(+)-\varepsilon-$ viniferin, wilsonol C, vitisin A, andvitisin B [43]. Acetone extract of stem bark of Shoreahopeifolia revealed the presence of oligostilbenes of $(\varepsilon)$-viniferin, $(-)$-ampelopsin E, (-)-hopeaphenol andshoreaphenol. (-)-hopeaphenolwasalsoisolated from Anisoptera species, acetone extract of the rhizome of Ampelocissusindica (L.) and stem bark ofVateriaindica Linn [2]. Similar oligostilbenes, vitisinol A, (+)- $\varepsilon$-viniferin, (+)-vitisin A, (-)-vitisin B, and (+)hopeaphenol were also isolated from Ampelopsis brevipedunculata var. hancei, of which the last three are tetramers [44]. (-)- $\varepsilon$-Viniferin, a dimer and a chiral molecule is regarded as the chemical marker of plants belonging to Dipterocarpaceae family and acts as a precursor of ologostilbenes found in Shorea, Hopea, Vatica and Dipterocarpus species. A trimer stilbene, ampelopsin E was isolated from Ampelopsis brevipedunculata and Shoreagibbosa. Shoreaphenol may be considered as the chemical marker of Shorea sp. and it is a dimer containing benzofuran ring [45]. Latifoliols A, B and C were detected in ethylacetate fraction of the Gnetumlatifolium extract. The first two compounds are characterised by a bridged 3-oxabicyclo [3.3.0] octane moiety, whereas latifoliol $C$ was producedby the condensation of gnemontanin $\mathrm{G}$ with trans-oxyresveratrol. Several oligostilbenes, such as cis-shegansu B, trans-shegansu B, gnetifolin F, (+)-gnemontanin $\mathrm{G}$, parvifolol C, lehmbachol B, gnetijolin C, gnetin $\mathrm{H}$ were reported in different plant species [40]. Preparative high performance liquid chromatography, NMR spectroscopy and mass spectrometric fragmentation pattern revealed the presence of several oligostilbenes namely, heimiol B, hopeaphenol, vaticanol A, balanocarpol and vaticaphenol $A$ in the crude extract of the leaves of Neobalanocarpusheimii [41]. The electrospray ionization ion-trap time-of-flight multistage mass spectrometry (ESI-IT-TOF-MSn) fragmentation study on (-)-7,8-cis- $\varepsilon$-viniferin, carasiphenol A, suffruticosol A and suffruticosol Cprovided valuable information for the fast characterization of oligostilbenes [46]. Several other resveratrol oligomers include trans-miyabenol $\mathrm{C}$, kobophenol $\mathrm{A}$ and kobophenol B isolated from Carexspecies (Carexfolliculata and Carexgynandra) and acuminatol, a dimer obtained from stem barks of Shoreaacuminata [47]. Miyabenol A was isolated from Vitis sp. Instrumental methods of analyses revealed the presence of vaticanol A, stepnophyllol C and hopeaphenol A in acetone extract of the stem bark of Shorea bracteolate [48]. Gnetulin is an isorhapontigenin dimer with 2,3-diphenyl-1-indane and exocyclic double bond framework isolated from different plants of Gnetum (Gnetaceae) and other analogs such as gnemuntanin $\mathrm{C}$ and $\mathrm{D}$, gnetuhainin, parthenocissin have also been reported [49]. With respect to stability, stilbenoids are vulnerable to effects of light, oxygen and temperature as well as oxidative enzymes. For example, exposure to UV and visible lights causes trans-to cis-isomerization of resveratrol [5]. Trans-gnetin $\mathrm{H}$ was converted to its cis-form on exposure to UV light for 6h [50]. Dryobalanopsoblongifolia Dyer was found to be a source of (-)-ampelopsin A, and two trimers, namely cis-and transdiptoindonesin B [51]. Structures of some representative oligostilbenes are presented in fig. 1.

\section{Stilbene glycosides}

Bioactivity-guided fractionation of the methanolic extract of Acer mono leaves showed the presence of two new stilbene glycosides, 5$O$-methyl- $(E)$-resveratrol 3- $O$ - $\propto$-D-glucopyranoside and 5- $O$-methyl(E)-resveratrol 3-O-â-D-apiofuranosyl-(1 $\rightarrow 6)$ - ? -D-glucopyranoside [52]. HR-ESI-MS, GC-MS, HPLC, NMR and other instrumental methods of analyses revealed five new stilbene glycosides, (E)$2,3,5,4^{\prime}$-tetrahydroxystilbene-2-0-(4' $-0-\alpha$-D-glucopyranosyl)- $\propto-$ D-glucopyranoside, (E)-2,3,5,4' tetrahydro-xystilbene-2-0-(6" -O$\propto$-Dglucopyranosyl)- $\propto$-D-glucopyranoside, tetrahydroxystilbene-2-0- $\propto$-Dglucopyranosyl-4' $-0-\alpha-D$ glucopyranoside, (E)-2,3,5,4 tetrahydroxystilbene-2-0- $\propto-\mathrm{D}-$ glucopyranosyl-5-0- $\alpha$-D-glucopyranoside, and (E)-2,3,5, $4^{\prime}$ tetrahydroxystilbene-2-0-(2" -0 - $\propto$-D-fructofuranosyl $)-\propto-\mathrm{D}$ glucopyranoside from the roots of Polygonummultiflorum [53].

Pharmacological effect and therapeutic potential of oligostilbenes

Ampelopsin A reportedly inhibited $A \beta$ aggregation in vitro [37]. Oligostilbenesgnetin $C$ (resveratrol dimer), gnetin $L$, gnemonoside $A$, gnemonoside $C$ and gnemonoside $D$ obtained from ethanolic extracts of the seeds of melinjo (Gnetumgnemon L.) exhibited free radical scavenging activity and antimicrobial activity against foodcontaminating microbes and Enterobacteriaceae [54]. The oligostilbenes isolated from G. macrostachyum inhibited lipoxygenase (sbLOX-1) either via non-competitive or mixedcompetitive mechanisms. It is to be mentioned that their enzyme inhibitory activity was not an outcome of their anti-oxidant effect. The compounds did not gain access to the enzyme catalytic site owing to their large molecular size [55]. Synergistic effect shown by a resveratrol tetramer with resveratrol monomer on inhibition of inflammatory arthritis was found to be stronger than the other oligomers isolated from stem part of Vitissp [42]. Vitisinol A, a resveratrol dimer demonstrated potent in vitro anti-inflammatory effect in LPS-induced RAW264.7 cells. It was found to be less cytotoxic compared to other dimer and tetramers isolated from Ampelopsissp [44]. cis-and trans-shegansu B and latifolol exhibited potential inhibitory effect against neuroinflammation induced by transfection of $A \beta 1-42$ gene into microglial BV-2 cell line. The tested compounds significantly lowered the secretion of NO in BV2 cells [40]. Among the oligostilbene isomers, cis-and transsuffruticosol D, obtained from the seeds of Paeoniasuffruticosa, trans-isomer showed greater cytotoxic effect (lower IC ${ }_{50}$ values) against several human cancer cell lines such as A549 (lung), BT20 (breast), MCF-7(breast), and U20S (osteosarcoma) versus normal human cell lines [HMEC (breast)and HPL1A (lung)]. Antitumor effects were characterised by the hall mark features of apoptotic pathway, including alteration in nuclear size and cell membrane permeability, decrease in mitochondrial transmembrane potential and lowering of cell motility. Excessive ROS generation by the oligostilbene isomers in lung cancer cells inhibited inducer cytokine production and blocked the NF-кBpathway [56]. Oligostilbenes, cis- $\varepsilon$-viniferin, trans- $\varepsilon$-viniferin, suffruticosol $\mathrm{A}$, suffruticosol B, suffruticosol C, cis-suffruticosol D, trans-suffruticosol D, cis-gnetin $\mathrm{H}$ and trans-gnetin $\mathrm{H}$, from the seedcases of $P$. suffruticosa demonstrated anti-proliferative activity and induced apoptosis in three representative subtypes of human breast carcinoma cells, including basal A phenotype BT20 cells [estrogen receptor (ER)-progesterone (PR)-human epidermal growth factor receptor 2 (HER2)-], luminal A phenotype MCF-7 cells (ER+PR+HER2-) and basal B phenotype MDA-MB-231 cells (ER-PR-HER2-). Higher efficacy was shown against BT20 cells than MCF-7 and MDA-MB-231 cells. Of the various compounds investigated, resveratrol dimers, trans and cis gnetin $\mathrm{H}$ exhibited 
maximum cytotoxic effect. Trimers were observed to be more potent than the dimers [50]. Ampelopsin E demonstrated selective cytotoxicity against cancer cells and thus could be developed as a promising chemotherapeutic agent [45]. cis-ampelopsin E inhibited LPS-induced inhibitor kinase $(\mathrm{IKK} \alpha / \beta)$ phosphorylation, cyclooxygenase-2 (COX-2) expression, cPLA2 activation and prostaglandin E2 (PGE2) production. Additionally, degradation of I $\kappa \mathrm{B} \alpha$ was prevented and upregulation of $\mathrm{NF}-\kappa \mathrm{B}$ transcriptional activity was inhibited via reduction of translocation of transcription factor p65 into the nucleus [57]. Cell cycle arrest has been cited as mechanism of anticancer effect of several oligostilbenes [47]. Mechanistic studies on deoxyrhapontigenin, a natural stilbene dimer derivative isolated from the root extract of Rheum undulatum displayed the compound to induce apoptosis and dilate endoplasmic reticulum(ER), upregulate the expression of ER stress markers GRP78, IRE1 $\alpha$, eIF $2 \alpha$, CHOP, JNK, and p38 in breast cancer cell line, chemoresistant MCF-7/adr[Chemoresistant (Doxorubicin/adriamycin) cell line] [58]. Acuminatol exhibited antioxidant activity, similar to resveratrol [47]. Among the oligostilbenes purified from grapevine root extract, vitisin B was identified as the most potent replication suppressor of hepatitis $\mathrm{C}$ virus (HCV) in vitro where it disrupted the activity of an essential viral enzyme, helicase NS3 [43]. (+) and (-)-hopeaphenol exerted antidiabetic effect via facilitation of glucose uptake in muscle cells by binding to the active sites of the proteins $1 \mathrm{BVN}$, $3 \mathrm{~A} 4 \mathrm{~A}$ and 3AJ7, thereby inhibiting $\alpha$-glucosidase in a dosedependent fashion. (-)-hopeaphenol inhibited bacterial virulence type III secretion system. An earlier research paper discussed several biological effects of hopeaphenol [2]. trans- $\varepsilon$-viniferin, trans-resveratrol dehydrodimer showed antimicrobial effect against Acetobacteraceti, Acetobacteroeni, Bacillus cereus, Bacillus subtilis, Dekkerabruxellensis, Escherichia coli, Listeria innocua, Listeria monocytogenes, Pseudomonas fluorescens, Pseudomonas aeruginosa, Streptococcus spp., Zygosaccharomycesbailii, and Zygosaccharomycesrouxii. Anti-obesity effect was also reported in rats. Adipogenesis was inhibited in 3T3-L1 cells by lowering levels of gene markers involved in lipid accumulation and expression of adipogenesis (PPARgamma) and anti-inflammatory (MCP-1) proteins [59]. Rhapontigenin and isorhapontigenin were found to possess weaker anti-staphylococcal effect against six standard strains and two clinical isolates of $S$. aureus, compared to hydroxypterostilbene, pinostilbene and pterostilbene [1]. (-)- $\varepsilon$ viniferin, (+)- $\alpha$-viniferin, (-)-hopeaphenol, vaticanols $A, B, C$ and G were reported to be weak inhibitors of murine tyrosinase [60]. Astringin, pallidol, $\omega$-viniferin, and $\varepsilon$-viniferinexhibited antiangiogenic effect. VEGF-induced PLC $\gamma 1$ phosphorylation was significantly inhibited.

Moreover, $\varepsilon$-viniferin and pallidol significantly induced NOS activation and thus could provide guard against the side effects caused by anti-VEGF hypertension drugs. Pallidol also inhibited VEGFR-2 activation [61]. Anti-malarial activity was shown by (-)ampelopsin $\mathrm{F}$, isolated from the acetone extract of the tree bark of Dryobalanopsoblongifolia Dyer [51]. Ampelopsin E lowered the invasive potential of triple negative breast cancer cells (MDA-MB231 cells) via reduction of formation of invadopodia, lowering the expression levels of PDGF, MMP2, MMP9 and MMP14 andarresting the cells' migration and transmigration. Resistance of K562/ADR cells to doxorubicin was also reversed, demonstrating synergism. Response to chemotherapy in treatment of hepatocellular carcinoma cells could be improved by ampelopsin E [62]. Cytotoxicity of circulating natural killer (NK) cells against K562 target cells was found to be higher in subjects receiving gnetin-C supplementation for two weeks. Absolute neutrophil count in the blood was also found to be lower than in the placebo group. Levels of several biochemical parameters of blood such as uric acid, lowdensity lipoprotein cholesterol, high-density lipoprotein cholesterol, total adiponectin, and high-molecular-weight adiponectin were also reduced significantly. Upregulation of the NKG2D and NKp46 receptors accounted for the immunomodulatory effects of gnetin $\mathrm{C}$, isolated from the seeds of Gnetumgnemon L [63]. Combination therapy of gnetin C with low dose of chemotherapeutic agents could increase the survival of immuno-deficient mice used as models of human acute myelogenous leukemia (AML). It actually blocked two pathways essential for the survival of leukemia cells, ERK1/2 and the AKT/mTOR pathways [54]. Anti-allergic effect of gnetin $\mathrm{H}$ is mediated through inhibition of histamine secretion, decreased production of TNF- $\alpha$, IL-4, suppression of translocation of NF- $\kappa \beta$, diminished expression of COX-2, suppression of phosphorylation of Syk, protein kinase $\mathrm{C}(\mathrm{PKC}) \mu$, phospholipase $\mathrm{C} \gamma$, and the mitogen-activated protein kinases, c-Jun N-terminal kinase, p38, and extracellular signal-regulated kinase, reduced secretion of $\beta$ hexosaminidase and inhibition of FceRI-mediated mast cell signaling and degranulation [64].

\section{Pharmacological effect and therapeutic potential of stilbene glycosides}

Stilbene glycosides isolated from the leaves of $A$. mono demonstrated excellent hepatoprotective effect when investigated against $\mathrm{H}_{2} \mathrm{O}_{2}$ induced oxidative damage in rat hepatocytes [52]. Naturally occurring stilbene glycoside, 2,3,5,4'-tetrahydroxydiphenylethylene2-O-glucoside was tested as apotential substrate for horseradish peroxidase (HRP)-catalyzedfluorogenic reactions to be utilised in fluorescence-based enzyme-linked immunosorbent assays (FELISA). It could be used for relatively sensitive, stable and faster assay of Brucellamelitensis antibody (BrAb) concentration in serum samples in clinical laboratory [65]. Stilbene glycoside isolated from the roots of $P$. multiflorum is expected to show beneficial effects in management of chronic diseases, such as apoplexy, senile dementia (Alzheimer's disease), hyperlipidemia and atherosclerosis. The compound, ' 2,3,5,4 -tetrahydroxystilbene-2-0- $\beta$-D-glycoside, attenuated the upregulation of Nrf2, HO-1, and NQO1, andthe downregulation of NF- $\kappa$ B induced by $\mathrm{H}_{2} \mathrm{O}_{2}$ in the $\mathrm{Nrf} 2$ signaling pathway in osteoblast-likeMC3T3-E1 cells. It also lowered the levels of caspase-3, caspase- 9 and Bax and increased the levelof Bcl-2. Thus, it could reverse $\mathrm{H}_{2} \mathrm{O}_{2}$-induced oxidative damage and may prove effective in therapeutic intervention of osteoporosis induced by oxidative injury [66]. In a different study on the mechanism of difference in anti-diabetic activity of trans-and cis-isomers of the same stilbene glycoside, 2,3,5,4 -tetrahydroxystilbene 2-O- $\beta$ glucopyranoside isolated from Polygonummultiflorum, it was observed that improvement of glucose intolerance was more with the cis-isomer. Both the isomers suppressed Dex/cAMP induced PEPCK transcription in HepG2 cell culture. Lowering of insulin resistance was also noted [67]. Among the two stilbene glycosides isolated from the medicinal plant Boswelliapapyriferia, the more hydrophilic compound, trans-4',5'-dihydroxy-3-methoxystilbene-50 - $\{\alpha$-L-rhamnopyranosyl- $(1 \rightarrow 2)-[\alpha$-L-rhamnopyranosyl- $(1 \rightarrow 6)\}$ - ? D-glucopyranoside inhibited FGF-2-induced proliferation, promoted wound healing and can be considered to possess anti-angiogenic activity [68].

\section{SAR of oligostilbenes and stilbene glycosides: General principles}

Biological activity, therapeutic effects and pharmacokinetic behaviour of stilbenoids depend greatly on the degree and position of hydroxylation and methoxylation. Introduction of methoxy substituent increases lipophilicity, resists metabolic degradation in vivo and facilitates easy penetration of the molecule across cell membrane, enhances the apoptotic activity of the phytocompound and ultimately improves the anticancer effect. However, too manymethoxy groups hinders interaction with the target protein and therefore becomes a barrier to its therapeutic efficacy $[33,69,70]$. Number and location of hydroxyl groups in the stilbene derivatives enhances aqueous solubility, alters the anti-oxidant property of the moleculeand improves the antimicrobial action [1]. It has been observed that presence of hydroxyl groups is essential for selective inhibition of COX-2 [71]. There are several studies confirming higher cytotoxic potential of cis-derivatives [10]. However, in a study on role of oligostilbenes in cancer management, trans-isomers have been found to be more effective. Antitumor efficacy of Paeonia oligostilbenes was governed by degree of polymerization i.e. the number of repeating units of resveratrol, presence of double bond, steric arrangement and their conformation. Both the isomers of gnetinH were found to be more cytotoxic than suffruticosol isomers. trans orientation of $\mathrm{H}-7^{\prime \prime} / \mathrm{H}-8^{\prime \prime}$ in cis-and trans-gnetin $\mathrm{H}$ may reduce steric hindrance between rings $\mathrm{C} 1$ and $\mathrm{C} 2$, thereby resulting in their higher bioactivity [50]. Anti-angiogenic effect of hydrophilic stilbene glycoside is attributed to the presence of bulky L-rhamnose residue and higher aqueous solubility [68]. 
<smiles>Oc1ccc(C=Cc2c3c(cc4c2[C@H](c2cc(O)cc(O)c2)[C@@H](c2ccc(O)cc2)O4)O[C@@H](c2ccc(O)cc2)C3c2cc(O)cc(O)c2)cc1</smiles>

trans-suffruticosol $D: 7^{\prime}, 8^{\prime}=$ trans cis-suffruticosol D : 7,', 8' = cis<smiles>[R6]c1cc(O)cc(/C=C/c2ccc(OC)c(O)c2)c1</smiles><smiles>COc1cc(/C=C/c2cc(O)cc(O)c2)ccc1O</smiles><smiles>Oc1ccc([C@H]2c3cc(O)cc4c3[C@@H](c3cc(O)cc(O)c32)[C@H](c2ccc(O)cc2)[C@@H](c2ccc(O)cc2O)[C@H]4c2ccc(O)cc2)cc1</smiles>

isohopeaphenol

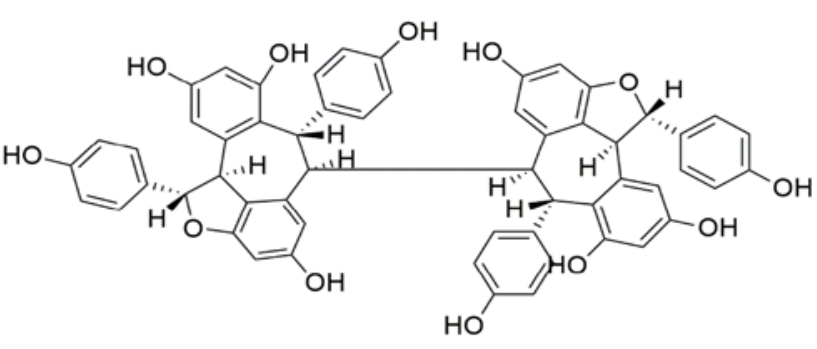

hopeaphenol<smiles>Oc1ccc(/C=C/c2cc(O)cc3c2C(c2cc(O)cc(O)c2)[C@@H](c2ccc(O)cc2)O3)cc1</smiles>

(+)- $\varepsilon$-viniferin<smiles>Oc1ccc([C@@H]2Oc3cc(O)cc4c3[C@@H](c3c(O)cc(O)cc32)[C@H](c2ccc(O)cc2)[C@@H]4O)cc1</smiles>

Ampelopsin A

Fig. 1: Structures of resveratrol and some representative oligostilbenes

\section{Pharmacokinetic studies on oligostilbenes and stilbene glycosides}

It has been reported that relatively small fraction of orally administered stilbenes are readily absorbed from the upper intestine. Stilbenes are characterised by low stability, rapid in vivo metabolism, poor bioavailability and low target specificity. Their bioavailability is affected by the compounds' pharmacokinetic parameters i.e., their absorption, distribution, metabolism and elimination. They may be excreted as metabolites either renally or non-renally [5]. A characteristic feature of plant polyphenols is that after oral administration, they are usually bioactive in their conjugated metabolite form produced as a result of enteric as well as hepatic Phase II biotransformation [7]. Colonic microflora also is involved in metabolic breakdown of large molecular weight nonabsorbed compounds to their lower MW derivatives [72]. Other factors governing their poor bioavailability include their chemical structure, degree of glycosylation/acylation, conjugation with other phenolic compounds, molecular size, degree of polymerization, solubility, route of administration etc [33]. Bioavailability studies help in planning the therapeutic uses and efficacy of the oligostilbenes.

Pharmacokinetic analysis of rhaponticin (rhapontin) in rats demonstrated rapid distribution and elimination and hence extremely poor oral bioavailability. However, the plasma concentration of rhapontigenin increased and eliminated gradually after parenteral administration [1]. Rhapontigenin was reported to 
have better bioavailability than resveratrol with a longer $t_{1 / 2}(3 \mathrm{~h})$ and it was also converted to its glucuronide and excreted via biliary route. The oligostilbene is characterized by high apparent volume of distribution suggesting its extensive tissue distribution [8]. Following oral administration at a dose of $100 \mathrm{mg} / \mathrm{kg}$ body weight in rats, half-life and oral bioavailability of gnetol were found to be $4.2 \mathrm{~h}$ and $6.59 \%$, respectively. Biotransformation of gnetol into its glucuronide and its reconversion back into parent stilbene accounted for its comparatively longer biological half-life. The glucuronide conjugate could be detected for $72 \mathrm{~h}$ in serum [5]. Poor bioavailability of vitisin B after ingestion is attributed to its large molecular size, poor aqueous solubility and low absorption across intestinal epithelium. Rapid and extensive in vivo metabolism of viniferin contributed to its low bioavailability. Enzymes UDPglucuronosyl transferase (UGT) and sulfotransferase (SULT) are involved in glucuronidation and sulfation of viniferin, leading to conjugates circulating in blood. However, intraperitoneal injection of viniferin reportedly improved its pharmacokinetic parameters with $85 \%$ bioavailability compared to $0.77 \%$ via oral route [43]. High bioaccumulation of the native compound was seen in white adipose tissues indicating them as body reservoir from where trans- $\varepsilon$ viniferin can be released slowly. Free oligostilbene was found in plasma as early as $15 \mathrm{~min}$ after intraperitoneal injection. A greater percentage of glucuronide metabolites could be detected in liver and kidney. Hepato-biliary excretion may be considered as major route of elimination for the particular isomer of viniferin as either native compound or its metabolites could be found more in faeces than in urine [59]. Poor bioavailability of trans- $\delta$-viniferin after oral administration was attributed to low absorption and extensive metabolism involving mainly glucuronidation and sulfation to a lesser extent. The molecule was excreted primarily in its unchanged form in the faeces [73]. Oral bioavailability of gnetin $C$ was found to be better than resveratrol [50]. Rate and extent of absorption of ampelopsin E were higher via intravenous route compared to oral route, owing to extensive first-pass metabolism (glucuronidation and sulfation) in the liver and small intestine [62].

\section{Future scope}

Translation of preclinical positive data for plant-derived oligostilbenes and stilbene glycosides on cell culture models and animals to human clinical setting requirelong-term randomized clinical studies with larger population samples of different age groups and longer follow-up periods [5]. Results obtained from these studies will establish therapeutic dose, and safe concentration of the bioactive phytochemicals. Although the whole plant or its parts form a part of the traditional diet due to their healthpromoting effects, there are limited studies on safety of the therapeutically active stilbenoids [63]. Trans-generational effects of these preventive dietary constituents should be investigated. Robust biomarkers should be developed to predict the safety and toxicity of the dietary phytochemicals [74]. Very few studies have reported the pharmacokinetic parameters of the oligostilbenes or the plantderived stilbene glycosides in humans. Little is known about the permeability of these molecules across blood-brain-barrier [34]. Studies on structure-activity relationship of the phytochemicals can provide new avenues for development of semi-synthetic and synthetic derivatives and hybrids possessing better solubility, metabolic stability and therapeutic efficacy [75]. Detailed mechanistic studies on chemopreventive effects and neuroprotective effects of the various oligostilbenes and stilbene glycosides discussed in the present chapter will open up possibilities and opportunities for these immensely potential phytochemicals of nutritional benefits.

\section{CONCLUSION}

From the above discussion, it is clearly evident that in spite of immense therapeutic potential of plant-derived oligostilbenes and stilbene glycosides, they generally suffer from bioavailability problems after oral administration owing to poor solubility and extensive pre-systemic and hepatic first-pass metabolism. Mechanistic investigations and elucidation of structure-activity relationship of this important class of secondary metabolites will help in discovery and development of novel semi-synthetic and synthetic derivatives and hybrids of natural phytochemicals for better therapeutic benefits.

\section{FUNDING}

Nil

\section{AUTHORS CONTRIBUTIONS}

All the authors have contributed equally.

\section{CONFLICT OF INTERESTS}

Declared none

\section{REFERENCES}

1. Zakova T, Rondevaldova J, Bernardos A, Landa P, Kokoska L. The relationship between structure and in vitro anti staphylococcal effect of plant-derived stilbenes. Acta Microbiol Immunol Hung 2018;65:467-76.

2. Sasikumar P, Prabha B, Reshmitha TR, Veluthoor S, Pradeep $\mathrm{AK}$, Rohit KR, et al. Comparison of antidiabetic potential of (+) and (-)-hopeaphenol, a pair of enantiomers isolated from Ampelocissusindica (L.) and Vateriaindica linn., with respect to inhibition of digestive enzymes and induction of glucose uptake in L6 myotubes. RSC Adv 2016;6:77075-82.

3. Błaszczyk A, Sady S, Sielicka M. The stilbene profile in edible berries. Phytochem Rev 2019;18:37-67.

4. Lim CG, Koffas MAG. Bioavailability and recent advances in the bioactivity of flavonoid and stilbene compounds. Curr Org Chem 2010;14:1727-51.

5. Akinwumi BC, Bordun KAM, Anderson HD. Biological activities of stilbenoids. Int J Mol Sci 2018;19:25.

6. Rencoret J, Neiva D, Marques G, Gutierrez A, Kim H, Gominho J, et al. Hydroxystilbeneglucosides are incorporated into Norway spruce bark lignin. Plant Physiol 2019;180:1310-21.

7. Krga I, Milenkovic D, Morand C, Monfoulet L. An update on the role of nutrigenomic modulations in mediatingthe cardiovascularprotective effect of fruit polyphenols. Food Funct 2016;7:3656-76.

8. Rimando AM, Suh N. Biological/chemopreventive activity of stilbenes and their effect on colon cancer. Planta Med 2008;74:1635-43.

9. Mizuno CS, Ampomaah W, Mendonça FR, Andrade GC, Silva AMN, Goulart MO, et al. Cytotoxicity and genotoxicity of stilbene derivatives in CHO-K1 and HepG2 cell lines. Gene Mol Bio 2017;40:656-64.

10. Piekus Słomka N, Mikstacka R, Ronowicz J, Sobiak S. Hybrid cisstilbene molecules: novel anticancer agents. Int J Mol Sci 2019;20:31.

11. Likhtenshtein GI. Stilbenes preparation and analysis in stilbenes. In: Applications in chemistry, life sciences and materials science. Weinheim: Wiley-VCH; 2010. p. 42.

12. Mekinic IG, Skroza D, Ljubenkov I, Katalinic V. Insight into the presence of stilbenes in medicinal plants traditionally used in Croatian folk medicine. Nat Prod Commun 2016;11:833-5.

13. Tsopmo A, Awah FM, Kuete V. Lignans and stilbenes from African medicinal plants. In: Kuete V. editor. Medicinal plant research in Africa: pharmacology and chemistry. New York: Elsevier; 2013. p. 435-78.

14. Antoni SJ, Rodriguez ML, Mena S, Asensi MA, Estrela JM, Ortega AL. Role of natural stilbenes in the prevention of cancer. Oxid Med Cell Longey 2016:15. DOI: 10.1155/2016/3128951

15. Mellal AA, Ahmed AS, Tran VH, Duke CC. The pharmacological effect of stilbenes isolated from kangaroo island propolis on sirt-1 enzyme activity. Int J Pharm Pharm Sci 2016;8:264-7.

16. Almagro L, Navarro SB, Sabater Jara AB, Vera Urbina JC, Selles Marchart S, Bru R, et al. Bioproduction of trans-resveratrol from grapevine cell cultures. In: KG Ramawat, JM Merillon. editors. Natural Products. Berlin, Heidelberg: Springer; 2013. p. 1683-713.

17. Baur JA, Sinclair DA. Therapeutic potential of resveratrol: the in vivo evidence. Nat Rev Drug Discovery 2006;5:493-507.

18. Tome Carneiro J, Larrosa M, Gonzalez Sarrias A, Tomas Barberan FA, Teresa M, Conesa G, et al. Resveratrol and clinical 
trials: the crossroad from in vitro studies to humanevidence. Curr Pharma Desi 2013;19:6064-93.

19. Berman AY, Motechin RA, Wiesenfeld MY, Holz MK. The therapeutic potential of resveratrol: a review of clinical trials. NPJ Precis Oncol 2017;35:9.

20. Zeka K, Arroo RRJ, Hassa D, Beresford KJM. New resveratrol analogues for potential use in diabetes and cancer diseases. Biomed J Sci Tech Res 2018;6:6.

21. Junsaeng D, Anukunwithaya T, Songvut P, Sritularak B, Likhitwitayawuid K, Khemawoot P. Comparative pharmacokinetics of oxyresveratrol alone and in combination with piperine as a bioenhancer in rats. BMC Complem Altern Med 2019;19:10.

22. Duangdee N, Chamboonchu N, Kongkiatpaiboon S, Prateeptongkum S. Quantitative ${ }^{1} \mathrm{HNMR}$ spectroscopy for the determination ofoxyresveratrol in Artocarpuslacucha heartwood. Phytochem Anal 2019;30:617-22.

23. Chatsumpun N, Chuanasa T, Sritularak B, Lipipun V, Jongbunprasert $\mathrm{V}$, Ruchirawat $\mathrm{S}$, et al. Oxyresveratrol: structural modification and evaluation of biological activities. Molecules 2016;21:9.

24. Tadtong S, Chatsumpun N, Sritularak B, Jongbunprasert V, Ploypradith P, Likhitwitayawuid K. Effects of oxyresveratrol and its derivatives on cultured P19-derived neurons. Trop J Pharm Res 2016;15:2619-28.

25. Lim YH, Kim KH, Kim JK. Source, biosynthesis, biological activities and pharmacokinetics of oxyresveratrol. Korean J Food Sci Technol 2015;47:545-55.

26. Wesołowska 0, Wisniewski J, Bielawska Pohl A, Paprocka M, Duarte N, Ferreira MJ, et al. Stilbenes as multidrug resistance modulators and apoptosis inducers in human adenocarcinoma cells. Anticancer Res 2010;30:4587-94.

27. Kumar A, Shih Yun L, Dhar S, Rimando AM, Levenson AS. Stilbenes inhibit androgen receptor expression in 22Rv1 castrate-resistant prostate cancer cells. J Med Act Plants 2014;3:1-8.

28. Hasriadi, Wong-on M, Lapphanichayakool P, Limpeanchob N. Neuroprotective effect of Artocarpuslakoocha extract and oxyresveratrol against hydrogen peroxide-induced toxicity in SH-SY5Y cells. Int J Pharm Pharm Sci 2017;9:229-33.

29. Lalitha V, Korah MC, Sengottuvel S, Sivakumar T. Antidiabetic and antioxidant activity of resveratrol and vitamin-C combination on streptozotocin induced diabetic rats. Int J Pharm Pharm Sci 2015;7:455-8.

30. Rajput SS, Kumar S, Metikurki B, Terai N, Schols D, Clercq ED, et al. Synthesis of stilbene-based resveratrol analogs as cytotoxic agents. Res J Pharm Biol Chem Sci 2016;7:1762-80.

31. Streicher W, Luedeke M, Azoitei A, Zengerling F, Herweg A, Genze F, et al. Stilbene induced inhibition of androgen receptor dimerization: implications for $\mathrm{AR}$ and $\mathrm{ABBD}$-signalling in human prostate cancer cells. PLOS One 2014;9:12.

32. Tripathi A, Misra K. Stilbene analogues as inhibitors of breast cancer stem cells through P-glycoprotein efflux; a 3D quantitative structure-activity relationship study (inhibitory activity of stilbenes analogues on breast cancer stem cells). Int Conf Bioinform Sys Biol 2016:4. DOI:10.1109/BSB.2016.7552134

33. Zakova IT. Anti-staphylococcal effect of plant-derived stilbenes [Dissertation]. Prague: Czech University of Life Sciences Prague; 2019.

34. Temsamani H, Krisa S, Merillon JM, Richard T. Promising neuroprotective effects of oligostilbenes. Nutr Aging 2015;3:49-54.

35. Hemingway RW, Hillis WE, Bruerton K. A gas-liquid chromatographic examination of stilbene derivatives. J Chromat 1970;50:391-9.

36. Chan STS, Popplewell WL, Bokesch HR, McKee TC, Gustafson KR. Five new stilbenes from the stem bark of Artocarpuscommunis. Nat Prod Sci 2018;24:266-71.

37. Biais B, Krisa S, Cluzet S, Da Costa G, Waffo Teguo P, Merillon $\mathrm{JM}$, et al. Antioxidant and cytoprotective activities of grapevine stilbenes. J Agric Food Chem 2017;65:4952-60.

38. Morita $\mathrm{H}, \mathrm{Abe}$ I. Structure and function of the chalcone synthase superfamily of plant type III polyketide synthases. Nat Prod Rep 2010;27:809-38.
39. Watts KT, Lee PC, Dannert CS. Biosynthesis of plant-specific stilbene polyketides in metabolically engineered Escherichia coli. BMC Biotechnol 2006;6:12.

40. Cho HM, Ha TKQ, Phama HTT, Ana JP, Huha J, Leea BW, et al. Oligostilbenes from the leaves of Gnetumlatifolium and their biological potential to inhibit neuroinflammation. Phytochem 2019;165:9.

41. Manshoor N, Fathil MF, Jaafar MH, Jalil MASA. Liquid chromatography-mass spectrometry dereplication strategy for isolation of oligostilbenes. Int J Appl Chem 2016;12:121-8.

42. Wang KT, Chen LG, Tseng SH, Huang JS, Hsieh MS, Wang CC. Anti-inflammatory effects of resveratrol and oligostilbenesfrom Vitisthunbergii var. taiwaniana against lipopolysaccharideinduced arthritis. J Agric Food Chem 2011;59:3649-65.

43. Lee S, Mailar K, Kim M, Park M, Kim J, Min D, et al. Plant-derived purification, chemical synthesis, and in vitro/in vivo evaluation of a resveratrol dimer, viniferin, as an $\mathrm{HCV}$ replication inhibitor. Viruses 2019;11:18.

44. Chang C, Chien WC, Huang KX, Hsu JL. Anti-inflammatory effects of vitisinol $A$ and four other oligostilbenesfrom Ampelopsis brevipedunculata var. hancei Molecules 2017;22:10.

45. Rohaiza S, Yaacob WA, Din LB, Nazlina I. Cytotoxic oligostilbenes from Shoreahopeifolia. Africa J Pharm Pharmacol 2011;5:1272-7.

46. Zhang C, Geng C, Jun J. A fragmentation study on four oligostilbenes by electrospray tandem mass spectrometry. Nat Prod Bioprosp 2019;9:279-86.

47. Navarro G, Martınez Pinilla E, Ortiz R, Noe V, Ciudad CJ, Franco R. Resveratrol and related stilbenoids, nutraceutical/dietary complements with health-promoting actions: Industrial production, safety, and the search for mode of action. Compr Rev Food Sci Food Safe 2018;17:808-27.

48. Norizan N, Ahmat N, Maulana Y, Shameeri Z. Isolation of oligostilbenes from Shorea bracteolate. Malaysian J Anal Sci 2016;20:1535-8.

49. Shang C, Kang Y, Yang Q, Zhu Q, Yao C. Versatile and enantioselective total synthesis of naturally active gnetulin. Adv Synth Catal 2019;361:3768-76.

50. GaoYand He C. Anti-proliferative and anti-metastasis effects of ten oligostilbenes from the seeds of Paeoniasuffruticosaon human cancer cells. Oncol Lett 2017;13:4371-7.

51. Indriani, Takaya Y, Puspaningsih NNT, Aminah NS. (-)Ampelopsin F, dimerstilbene compound from Dryobalanopsoblongifolia and antimalarial activity test. Chem Nat Comp 2017;53:559-61.

52. Yang H, Sung SH, Kim YC. Two new hepatoprotective stilbene glycosides from Acer mono leaves. J Nat Prod 2005;68:101-3.

53. Li SG, Chen LL, Huang XJ, Zhao BX, Wang Y, Ye WC. Five new stilbene glycosides from the roots of Polygonummultiflorum. J Asian Nat Prod Res 2013;15:1145-51.

54. Espinoza JL, Elbadry MI, Taniwaki M, Harada K, Trung LQ, Nakagawa $\mathrm{N}$, et al. The simultaneous inhibition of the mTOR and MAPK pathways with gnetin-C induces apoptosis in acute myeloid leukemia. Cancer Lett 2017;400:127-36.

55. Surapinit S, Sri-inb P, Tip-pyang S. Highly potent oligostilbene sbLOX-1 inhibitor from Gnetummacrostachyum. Nat Prod Commun 2014;9:970-4.

56. Almosnid NM, Gao Y, He C, Park HS, Altman E. In vitro antitumor effects of two novel oligostilbenes, cis-and transsuffruticosol D, isolated from Paeoniasuffruticosa seeds. Int J Oncol 2016;48:646-56.

57. Cai T, Cai Y. Cis-ampelopsine, a stilbene isolated from the seeds of Paeoniasuffruticosa, inhibits lip polysaccharide-stimulated nitric oxide production in RAW 264.7 macrophages via blockade of nuclear factor-kappa Bsignaling pathway. Biol Pharm Bull 2011;34:1501-7.

58. Venkatesan T, Jeong MJ, Choi YW, Park EJ, Desouky SK, Kim YK. Deoxyrhapontigenin, a natural stilbene derivative isolated from Rheum undulatum $\mathrm{L}$. induces endoplasmic reticulum stressmediated apoptosis in human breast cancer cells. Integr Cancer Ther 2016;15:NP44-52.

59. Courtois A, Atgie C, Marchal A, Hornedo Ortega R, Lapeze C, Faure $\mathrm{C}$, et al. Tissular distribution and metabolism of trans- 
viniferin after intraperitoneal injection in rat. Nutrients 2018;10:11.

60. Likhitwitayawuid K. Stilbenes with tyrosinase inhibitory activity. Curr Sci 2008;94:44-53.

61. Fernandez Cruz E, Cerezo AB, Cantos Villar E, Richard T, Troncoso AM, Garcia Parrilla MC. Inhibition of VEGFR-2 phosphorylation andffeets on downstream signaling pathways in cultivated human endothelial cells by stilbenes from Vitisspp: J Agric Food Chem 2019;67:3909-18.

62. Tieng FYF, Latifah SY, MdHashim NF, Khazaai H, Ahmat N, Gopalsamy BWA. Ampelopsin E reduces the invasiveness of the triple negative breast cancer cell line, MDA-MB-231. Molecules 2019;24:25.

63. Nakagami Y, Suzuki S, Espinoza JL, Quang LV, Enomoto M, Takasugi $\mathrm{S}$, et al. Immunomodulatory and metabolic changes after gnetin-c supplementation in humans. Nutrients 2019;11:16.

64. Kim M, Lim SJ, Oidovsambuu S, Nho CW. Gnetin H isolated from Paeoniaanomalainhibits FceRI-mediated mast cell signaling and degranulation. J Ethmo Phrarmacol 2014;154:798-806.

65. Zhan XH, Gong FC, Tan SZ, Huang PM, Tan YF. An immunosensing system using stilbene glycoside as afluorogenic substrate for an enzymatic reaction model. Sensors 2008;8:5661-72.

66. Cheng J, Wang H, Zhang Z, Liang K. Stilbene glycoside protects osteoblasts against oxidative damage via Nrf2/HO-1 and NF- $\mathrm{KB}$ signalling pathways. Arch Med Sci 2019;15:196-203.

67. Tang W. Hypoglycemic effects of stilbene glycoside from Polygonummultiflorumin type 2 diabetes and its mechanism of action [Dissertation]. The State University of New Jersey; 2015.
68. Hussain S, Slevin M, Ahmed N, West D, Choudhary MI, Naz HGJ Stilbene glycosides are natural product inhibitors of FGF-2inducedangiogenesis. BMC Cell Biol 2009;10:12.

69. Tsai HY, Chi Tang Ho CT, Yu Kuo Chen YK. Biological actions and molecular effects of resveratrol, pterostilbene, ánd 3 hydroxypterostilbene. J Food Drug Anal 2017;25:134-47.

70. Zhang L, Zhou GZ, Song W, Tan XR, Guo YQ, Zhou B, et al. Pterostilbene protects vascular endothelial cells against oxidized low-density lipoprotein-induced apoptosis in vitro and in vivo. Apoptosis 2012;17:25-36.

71. Kutil Z, Kvasnicova M, Temml V, Schuster D, Marsik P, Cusimamani EF, et al. Effect of dietary stilbenes on 5lipoxygenase and cyclooxygenases activities in vitro, Int J Food Prop 2015;8:1471-7.

72. Hornedo Ortega R, Cerezo AB, DePablos RM, Krisa S, Richard T, Garcia Parrilla MC, et al. Phenolic compounds characteristic of the Mediterranean diet in mitigating microglia-mediated neuro inflammation. Front Cell Neurosci 2018;12:20.

73. Mao P, Lei Y, Zhang T, Man C, Jin B, Li T. Pharmacokinetics, bioavailability, metabolism and excretion of $\delta$-viniferin inrats. Acta Pharma Sin B 2016;6:243-52.

74. Schnekenburger M, Diederich M. Nutritional epigenetic regulators in the field of cancer: new avenues for chemo preventive approaches. In: SG Gray, editor. Epigenetic cancer therapy. New York: Elsevier; 2015. p. 393-425.

75. Hassan AHE, Choi E, Yoon YM, Lee KW, Yoo SY, Cho MC, et al. Natural products hybrids: 3,5,4'-trimethoxystilbene-5,6,7trimethoxyflavone chimeric analogs as potential cytotoxic agents against diverse human cancer cells. Eur J Med Chem 2019;161:559-80. 